\title{
Corte Suprema y participación ciudadana: reflexiones a partir de una audiencia pública de la Corte argentina*
}

\author{
Supreme Court and Public Participation: Reflections from \\ a Public Hearing in the Argentine Court \\ Corte Suprema e participação cidadã: reflexões a partir \\ de uma audiência pública da Corte argentina
}

\author{
LETICIA BARRERA * \\ JIMENA SÁENZ
}

FeChA DE RECEPCIÓN: 31 DE ENERO DE 2019. FECHA DE APROBACIÓN: 31 DE MAYO DE 2019

Doi: http://dx.doi.org/10.12804/revistas.urosario.edu.co/sociojuridicos/a.8069

Para citar: Barrera, L. \& Sáenz, M. J. (2019). Corte Suprema y participación ciudadana: reflexiones a partir de una audiencia pública de la Corte argentina. Revista Socio Jurídicicos, 22(1), 263-291. Doi: http://dx.doi.org/10.12804/revistas. urosario.edu.co/sociojuridicos/a.8069

\section{RESUMEN}

Las audiencias públicas que en la última década han instaurado los altos tribunales de Latinoamérica han sido consideradas uno de los puntos más novedosos en las prácticas constitucionales que abren la promesa de un vínculo más estrecho entre las instituciones judiciales y la ciudadanía. En este sentido, la apertura a la participación de la ciudadanía es

* Una primera versión de este trabajo fue presentada en el seminario Justicia y Política, llevado a cabo en el marco del Congreso de la Sociedad Argentina de Análisis Político (SAAP), celebrado en la Universidad Torcuato Di Tella (UTDT), el 1 de agosto de 2017. Las autoras agradecen los comentarios recibidos en aquella oportunidad. Así mismo, agradecen a los vecinos de la Cuenca Matanza-Riachuelo, funcionarios de la Ciudad de Buenos Aires, y representantes de las ONG que entrevistaron a lo largo de este trabajo y que generosamente compartieron su tiempo, vivencias y saberes sobre este conflicto que los afecta cotidianamente. Por último, se incluye un especial agradecimiento a Miguel Á. Benedetti que compartió sus notas de campo, hizo posibles las entrevistas y brindó sugerencias bibliográficas, así como comentarios centrales sobre lo que aquí se presenta.

** Doctora en Ciencias Jurídicas de la Universidad de Cornell, Estados Unidos. Investigadora del CONICET con sede en el Instituto de Altos Estudios Sociales de la Universidad Nacional de San Martín, Argentina. Se especializa en el estudio del derecho y la práctica judicial desde una perspectiva sociocultural. Correo electrónico: leticiabarrera@yahoo.com. ORCID: https://orcid. org/0000-0002-7001-9378

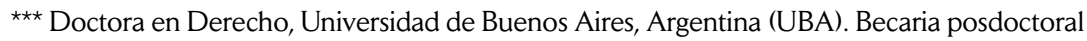
del CONICET-Universidad Nacional de La Plata (UNLP). Profesora de Derecho Constitucional y Teoría del Derecho (UNLP-UBA). Correo electrónico: mjimenasaenz@hotmail.com. ORCID: https://orcid.org/0000-0002-6954-372X 
la dimensión que ha acaparado las miradas de la teoría constitucional democráticamente orientada. Este trabajo se pregunta sobre los términos de la participación ciudadana en el ámbito de la Corte Suprema argentina, sobre el tipo de tensiones que se generan cuando ingresan al espacio cortesano actores ajenos a sus quehaceres y con ellos, nuevas formas de expresión y nuevas narrativas sobre los casos. Para ello, nos detenemos en una audiencia particular celebrada en noviembre de 2016, en un caso emblemático de lo que en su momento se denominó "la nueva Corte", instaurada luego de la crisis de 2001. En el artículo ofrecemos una reflexión situada sobre lo que está en juego en las audiencias y en esta audiencia en particular, con base en registros etnográficos,entrevistas, observaciones de campo, análisis del expediente y fuentes secundarias, a la luz de los planteos teóricos del constitucionalismo democrático.

Palabras clave: audiencias públicas, Corte Suprema, participación ciudada, deliberación pública, derecho constitucional.

\begin{abstract}
In the last decade, many Supreme Courts in Latin America have adopted public hearings as a part of their decision-making process. This novel phenomenon in these tribunals' constitutional law practice has been seen as a unique opportunity to tight the links between the judiciary and the citizenry. Matter-of-factly, the highest courts' decision to open up decision-making to public participation has been stressed by a constitutional theory that advances democracy in judicial adjudication. This work inquires on public participation in the context of Argentine Supreme Court by pointing out the tensions, discourses, and different perspectives on the cases that the coming of new actors to the judicial arenaother than those who usually stand before the Court-instantiate. To do so, we focus on a particular public hearing held by the Argentine Court in November 2016, in a landmark case decided by the so-called new Court, established in the aftermath of the 2001 crisis. From the ethnographic data collected from interviews, field observation, analysis of the case file, and secondary sources, we propose a situated reflection on the issues at stake in public hearings, in this hearing in particular, through the lens of the democratic constitutional theory.
\end{abstract}

Keywords: Public hearings, Supreme Court, public participation, public deliberation, constitutional law.

\title{
RESUMO
}

As audiências públicas que na última década têm instaurado os altos tribunais de LatinoAmérica têm sido consideradas um dos pontos mais inovadores nas práticas constitucionais que abrem a promessa de um vínculo mais estreito entre as instituições judiciais e a cidadania. Neste sentido, a apertura à participação da cidadania é a dimensão que tem dominado os olhares da teoria constitucional democraticamente orientada. Este trabalho se pergunta sobre os termos da participação cidadã no âmbito da Corte Suprema Argentina, sobre o tipo de tensões que se geram quando ingressam ao espaço cortesão, atores alheios a seus afazeres e com eles, novas formas de expressão e novas narrativas sobre os casos. Para isto, detemo-nos em uma audiência particular celebrada em novembro de 2016, em um caso emblemático do que em seu momento denominou-se "a nova Corte" instaurada após da crise de 2001. No artigo oferecemos então uma reflexão situada sobre o que está em jogo nas audiências e nesta audiência em particular, em base a registros etnográficos, entrevistas, observações de campo, análises do expediente e fontes secundárias, à luz das propostas teóricas do constitucionalismo democrático.

Palavras-chave: audiências públicas, Corte Suprema, participação cidadã, deliberação pública, direitoconstitucional. 


\section{Introducción}

Las audiencias públicas que en la última década han instaurado los altos tribunales de Latinoamérica han sido consideradas uno de los puntos más novedosos en las prácticas constitucionales que abren la promesa de un vínculo más estrecho entre las instituciones judiciales y la ciudadanía. En este sentido, la apertura que plantean a la participación ciudadana es la dimensión que ha acaparado la mirada de la teoría constitucional democráticamente orientada (Mendes, 2013; Gargarella \& Bergallo, 2014; Tushnet, 2015).

Dichas audiencias transcurren en las cortes supremas, sitios que condensan la autoridad del derecho, pero conjugan de distintas maneras un "adentro" que se pretende claramente delimitado, y un "afuera" que se introduce al menos durante su realización allí, cuando las cortes reciben a distintos actores sociales que participan de uno u otro modo en los casos. Ligado a esto último, en su lectura etnográfica, Greenhouse (2012) plantea a las audiencias como una instancia distintiva de la judicialización de la política, y desde la teoría constitucional, Tushnet (2015) las ha caracterizado en un sentido semejante, como espacios "híbridos" que se ubican entre los foros de discusión políticos y judiciales, y en el caso de aquellas que se abren en las altas cortes, espacios donde la interpretación constitucional se presenta como una "mezcla entre política y derecho". Otros autores interesados en un constitucionalismo sensible a la voluntad popular, han considerado a las audiencias -aunque refiriéndose a aquellas en las que se confirma o no la designación de los jueces y que tienen lugar en foros políticos- como sitios donde puede negociarse la "tensión entre derecho y política [que] irradia la democracia constitucional" (Post E Siegel, 2013, p. 46), por un lado plantean la necesidad de que la tarea de las cortes de reafirmar los compromisos constitucionales cuente con legitimidad democrática y se abran a recibir a distintos actores sociales y políticos en los procesos decisorios; y por otro lado, deben mantener su independencia de la influencia de la política (Post \& Siegel, 2013). En este sentido, las audiencias en la sede judicial, y sobre todo en las altas cortes, pueden pensarse como un espacio donde se trasladan o traducen modos de participación que usualmente se asocian a los espacios políticos, hacia los espacios reservados del poder judiciale intentan conjugar 
la necesidad de sostener "la razón jurídica profesional" para "separar a la política del derecho", con la necesidad de que sus decisiones resulten sensibles a la voluntad de la ciudadanía y la incluyan de algún modo en los procesos decisorios (Post \& Siegel, 2013, pp. 46-47).

Algo semejante sugieren los constitucionalistas "dialógicos" que también se muestran partidarios de incluir dentro de las Cortes -especialmente en aquellas que guardan para sí la facultad del control de constitucionalidad en última instancia-espacios deliberativos que conserven aún dentro de una institución "contramayoritaria", "una huella del autogobierno colectivo" y que en lugar de poner un punto final a una controversia, promuevan el diálogo democrático dentro y fuera de sus estrados (Mendes, 2013; Gargarella \& Bergallo, 2014).

En ese marco, este trabajo se pregunta sobrelos términos de la participación ciudadana en el proceso judicialtal como se presentan en la práctica y sobre el tipo de tensiones que se generan cuando ingresan al espacio cortesano actores tradicionalmente ajenos a sus quehaceres, quienes a su vez introducen también nuevas formas de expresión y nuevas narrativas sobre los casos. Para ello, nos detenemos en una audiencia particular celebrada en noviembre de 2016, en un caso emblemático de lo que en su momento se denominó "la nueva Corte" instaurada luego de la crisis de 2001: el caso "Mendoza".

El ritual de esa audiencia implicó para nosotros, que participamos en ella en calidad de "público" observador, fijar la atención en algunos actores sociales presentes en ese acto, los cuales se situaron en los límites o márgenes del espacio consolidado de las audiencias. Estos actores permanecieron en su mayoría estrictamente fuera de la sala de audiencias del Tribunal o en los márgenes de ese recinto, en un espacio contiguo que se conoce como "Patio de Honor" y que fue habilitado por la Corte para el público interesado en "presenciar" tal acontecimiento.

La observación del acontecer de una audiencia pública en particular en el ámbito de la Corte Suprema argentina funcionó como punto de partida para nuestra indagación que intenta volver visible y darle inteligibilidad a la presencia, las voces y las prácticas de esos actores sociales de 
otro modo invisibles a las perspectivas jurídicas que limitan el derecho a las sentencias y otros documentos, los argumentos, la teoría abstracta o que focalizan en la mirada de los tribunales. Como forma de conocimiento, la observación etnográfica privilegia la experiencia, "lo que permite introducirse en los dominios de lo social que no son de fácil acceso si se siguen los protocolos formales de los que se sirven otras disciplinas" (Das E Poole, 2008, p. 20). Si bien, como destaca Guber (2001), "el trabajo de campo etnográfico se caracteriza por su falta de sistematicidad [frente allos procedimientos de otras ciencias sociales, [sulambigüedad es, más que un déficit, su cualidad distintiva" (pp. 55-56). La llamada "observación participante" o etnográfica es, según la autora, "una valiosa ayuda para el conocimiento social porque evita algunas mediaciones [...] ofreciendo a un observador crítico lo real en toda su complejidad [...] es el medio ideal para realizar descubrimientos, para examinar críticamente los conceptos teóricos y para anclarlos en realidades concretas, poniendo en comunicación distintas reflexividades" (Guber, 2001, p. 62).

El análisis que aquí se presenta se apoya en una estrategia teóricometodológica que combina los aportes del método etnográfico, complementado con el análisis del expediente, las actas y el registro fílmico de la audiencia y entrevistas en profundidad realizadas a distintos actores clave $^{2}$ con categorías analíticas enunciadas por la teoría constitucional contemporánea sensible a los actos y las opiniones de los ciudadanos respecto a las decisiones judiciales (Post \& Siegel, 2013; Gargarella, 2014). ${ }^{3}$

2 Entrevistamos a delegados vecinales de la Villa 21-24, representantes de Organizaciones No Gubernamentales (ONG) con trabajo en el territorio, y funcionarios de la defensa pública a cargo del patrocinio letrado de los vecinos de la cuenca Matanza-Riachuelo. Todas las entrevistas fueron realizadas durante 2017.

3 En este punto es necesario introducir una aclaración sobre el ámbito y alcance de este trabajo. No nos ocuparemos aquí de desarrollar en extenso los debates teóricos vinculados al constitucionalismo sensible a la voluntad popular o a las prácticas ciudadanas en relación a la Constitución. Nos interesa querríamos conservar esto, eventualmente reemplazar por "en cambio" tomar algunos elementos teóricos planteados en ese seno para reflexionar sobre fenómenos jurídicos, como nuestra audiencia en particular, que implican relaciones entre las Cortes y la participación ciudadana. En otros términos, más que avanzar en la discusión teórica abstracta, nos interesa ver cómo funcionan esas perspectivas en nuestra práctica local y estimular líneas de investigación y testeo empírico sobre ellas. En este sentido, nos centramos en una corriente del constitucionalismo sensible a la ciudadanía o democráticamente orientado que mantiene un rol importante para el poder judicial: la propuesta del "constitucionalismo democrático" de Post y Siegel, y en parte el "constitucionalismo dialógico" avanzado por Gararella. Dejamos fuera entonces otros desarrollos del "constitucionalismo popular" como el de Kramer (2004). 
En su conjunto, este abordaje nos permitió explorar de cerca una audiencia singular convocada en la Corte Suprema argentina en noviembre de 2016. Los sucesos de esa audiencia pusieron en primer plano las dificultades que ponen en escena las audiencias públicas desde las perspectivas presentadas: conjugan la política y el derecho, enlazan la voz usualmente monolítica de las cortes y las múltiples perspectivas que se plantean entre los sectores implicados en la decisión de los casos, ponen en escena la relación conflictiva entre la voz de la experticia y la huella del ideal de autogobierno.

En lo que sigue, el trabajo empieza por exponer las vicisitudes principales del caso elegido, y su importancia institucional, así como la práctica de audiencias de la Corte argentina, es decir, intentamos esbozar una respuesta al por qué este caso y esta audiencia como foco de análisis, y contextualizar el análisis que se propone. Luego, se exploran las conjunciones que se tensionan en las audiencias a partir de dos viñetas etnográficas que recuperamos de nuestras observaciones en el edificio de los tribunales porteños, sede de la Corte argentina; con estas se buscan recuperar dos momentos clave de la audiencia de noviembre de 2016 que permiten vislumbrar, como un dato que surge del trabajo de campo, la palpable tensión que se activa al poner en escena la instancia participativa en el interior del tribunal y cómo sus efectos irradian una concepción más general acerca del proceso judicial, los modos de intervención en el mismo y el lugar de la justicia. La primera rastrea la difícil convivencia durante la audiencia entre modos de expresión asociados usualmente a los foros políticos y aquellos vinculados a la experticia y la calma razón profesional del derecho. La segunda, se centra en el espacio de la audiencia como espacio de intersección o entrelazamiento de perspectivas sobre el caso que pone en cuestión la univocidad de las sentencias judiciales y la unidad e independencia de la voz judicial de la Corte, o lo que también se ha llamado su monopolio interpretativo. Sobre el final, recuperamos los hallazgos de la investigación que presentamos y esbozamos algunas notas conclusivas. 


\section{El caso "Mendoza" y las audiencias públicas en la Corte argentina}

La causa que enmarca nuestra reflexión es la que la Corte Suprema argentina lleva adelante desde 2006 hasta la actualidad en relación con la contaminación de la cuenca del río Matanza-Riachuelo. ${ }^{4} \mathrm{El}$ caso tiene una importancia destacada tanto en la línea jurisprudencial como en relación a la historia institucional reciente de la Corte argentina, así como respecto de la práctica de las audiencias públicas.

En efecto, "Mendoza" atrveasó un período de renovación institucional de la Corte Suprema, marcado por la necesidad y la preocupación de sus miembros por recuperar la confianza de los ciudadanos en la autoridad judicial luego del descredito que la crisis del 2001-2002 vino a cristalizar, además de un intento por establecer un vínculo diferente con los poderes políticos y el resto del poder judicial. Así, suele considerárselo como uno de los casos clave de la agenda del Tribunal diseñada después de la crisis, que amplió los límites de lo justiciable para incluir problemas de alta visibilidad e impacto social como la limpieza del Riachuelo, y que requerían a su vez nuevas formas procesales. ${ }^{5}$ Por otra parte, y ligado a

4 La cuenca Matanza-Riachuelo es la región ambiental y socialmente más degradada de Argentina. Se encuentra localizada al noreste de la provincia de Buenos Aires y constituye el límite sur de la Ciudad de Buenos Aires, que la conecta con el resto de la provincia. Es una zona industrial, que atraviesa a la ciudad y a catorce municipios provinciales, donde habitan más de 6 millones de personas que viven en villas, barrios y asentamientos precarios. Para más información ver http://www.acumar.gob.ar

5 El caso Riachuelofue leído como parte de un "nuevo rumbo" en la agenda del tribunal junto a una serie que, a la par de ampliar el terreno de la discusión legal, también incluyó la convocatoria a audiencias públicas. En este sentido, Paola Bergallo caracteriza la intervención de la Corte en el caso Riachuelo como "un primer viraje en su aproximación a las vulneraciones del derecho a la salud y el medio ambiente sano" (Bergallo, 2014, p. 258); por su parte, Mariela Puga lo presenta como parte de "una nueva tendencia [...] compuesta por dos características: [...] la nueva Corte interviene decididamente en causas de derecho público, colectivas y complejas, que tradicionalmente se excluían como cuestiones políticas no justiciables [...]" y "la Corte interviene en estos casos inaugurando procesos abiertos en el tiempo, en el que se monitorean y revisan instituciones y/o políticas, dictando medidas multiformes que escapan al marco más convencional de medidas prácticas detalladas dirigidas directamente a hacer satisfacer un derecho" (Puga, 2008, p. 152). Desde la perspectiva ambiental, Cafferata (2007) y Berros (2012) la consideran "una de las [causas] más importantes en materia medioambiental del supremo tribunal argentino en el último período" (Berros, 2012, p. 115). Con un interés en las formas que puede asumir el "constitucionalismo dialógico", Roberto Gargarella y Paola Bergallo consideraron al caso Riachuelo como uno en el que la Corte "optó por transitar un camino alternativo, absolutamente inusual y de carácter esencialmente dialógico o conversacional” (Gargarella \& Bergallo, 2014, p. 11). 
esto último, se incluyó la práctica de las audiencias públicas en el proceso decisorio judicial, y el caso también tuvo un lugar prominente en los intentos de reorganización interna del Tribunal enauguró una serie de estrategias comunicativas sin precedentes hasta el momento. ${ }^{6}$

En relación con la incorporación de audiencias públicas como parte del proceso decisorio y luego como parte del repertorio institucional del Alto Tribunal, desde la intervención inicial de la Corte en el caso "Mendoza", la apertura de espacios de diálogo y la participación de los diferentes actores involucrados-entre los que estaban distintos niveles y agencias de gobierno, un numeroso grupo de empresas, diversas organizaciones de la sociedad civil y amplias franjas de la población que habitan la contaminada cuenca- se presentó como una de las características centrales del proceso judicial.

Entre 2006 y 2007, antes de que la Corte dictara sentencia, se realizaron cuatro audiencias públicas que en varios casos insumieron más de una jornada; luego de la sentencia de 2008, se convocaron otras tres audiencias destinadas a monitorear la implementación de la decisión en 2011 y 2012; y por último se realizaron otras el 30 de noviembre de 2016 el 14 de marzo de 2018. Luego de la experiencia de las primeras audiencias en la causa, se formalizó la práctica como parte del repertorio institucional del Supremo Tribunal mediante la Acordada 30/2007, que tiene como uno de sus antecedentes más importantes la reglamentación ad-hoc que se había establecido en Mendoza. ${ }^{7}$ Por su parte, las audiencias de supervisión y seguimiento que se realizaron luego de la

6 Desde 2011, luego de la repercusión pública de la sentencia del caso "Riachuelo" (2008), el proceso de reorganización interna le otorgó un lugar especial a la materia ambiental. Así, por la Ac. 35/2011 se estableció la Norma y el Sistema de Gestión Ambiental para la Corte; la Ac. 16/2013 creó la Comisión de Ambiente y Sustentabilidad; la Ac. 1/2014 creó la Oficina de Justicia Ambiental bajo la superintendencia directa de la Corte; y finalmente, la Ac. 8/2015 creó una secretaría especial para la tramitación y gestión "de litigios masivos de casos ambientales que tengan por objeto el bien colectivo ambiente o alguno de sus componentes". El caso cuenta también con una sección especialdentro de la web del Centro de Información Judicial (CIJ), que incluye una inédita documentación en soporte digital de todo el expediente ante la Corte y un documental sobre el Riachuelo (http://www.cij.gov.ar/riachuelo.html).

La Ac. 30/2007 establece once "reglas básicas" para el desarrollo de las audiencias. Allí se clasifica a las audiencias como "informativas", que tienen por objeto "escuchar e interrogar a las partes"; "conciliatorias", para "instar a las partes a la búsqueda de soluciones no adversariales"; y "ordenatorias", con la finalidad de "tomar las medidas que permitan encauzar el procedimiento a fin de mejorar la tramitación de las causas" (Regla 2). Las reglas siguientes se dirigen a ordenar los momentos previos a la audiencia (cómo se convocan, qué casos se seleccionan para realizar- 
sentencia, no estaban contempladas en la tipología que estableció la Acordada 30/2007, y emergieron con el desarrollo de la práctica en el caso Riachuelo durante los primeros años de vida de la regulación oficial (Benedetti \& Sáenz, 2016).

Además de su rol inaugural de la práctica de audiencias, este caso se mantuvo a lo largo del tiempo como un caso faro, que ilumina la práctica y marca el ritmo de su desarrollo: Mendoza es la única de todas las causas en las que se convocó a audiencias que cuenta con numerosas y particulares jornadas de audiencias en un periodo de más de diez años.

Por estas razones, el caso se presenta como una especie de termómetro de la práctica, que permite rastrear sus potencialidades así como sus problemas.

Para ubicar la audiencia que aquí interesa y recorrer algunas de las características particulares del caso, puede esquematizarse su desarrollo en dos grandes etapas (antes y después de la sentencia de 2008), y una segunda dividida a su vez en dos subetapas de la ejecución de la sentencia. La figura 1 presenta este esquema ubicando las audiencias públicas celebradas hasta la del 30 de noviembre de 2016 que nos ocupa.

Figura 1. Las audiencias del caso Mendoza

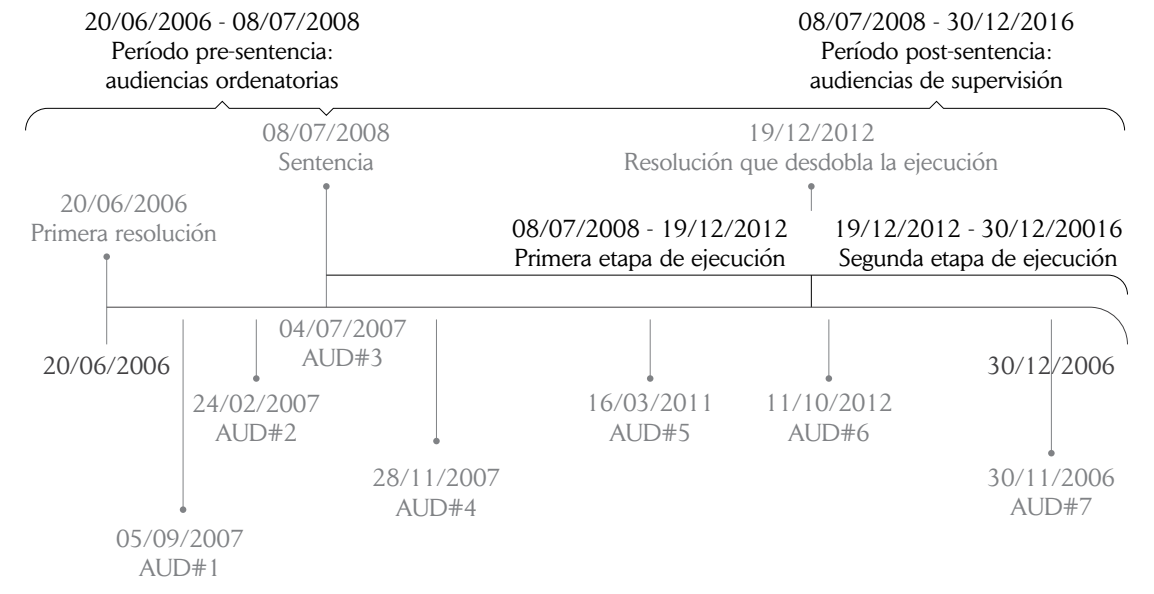

Fuente: elaboración propia.

las); el acto de la audiencia (posibilidad de interrogar a los expositores, tiempo de exposición); y el momento posterior (registro y difusión de la audiencia). 
La causa que había sido iniciada por un grupo de vecinos y profesionales de la cuenca Matanza-Riachuelo tuvo su primera resolución dictada por la Corte en junio de $2006 .^{8}$ Allí, además de determinarse el ámbito de la competencia originaria del Tribunal, se convocó a una primera audiencia pública en la que las empresas demandadas debían presentar información sobre sus actividades en la cuenca, y los distintos niveles gubernamentales involucrados -el Estado Nacional, la provincia y la Ciudad Autónoma de Buenos Aires (CABA) - debían proponer un "plan integrado" de saneamiento ambiental de la zona. Poco tiempo después, la Corte aceptó la participación procesal como terceros de la Defensoría del Pueblo de la Nación y de un grupo de organizaciones de la sociedad civil.

A esa primera audiencia pública, le siguieron otras tres durante el bienio 2006-2007. En ellas se generó un primer espacio de comunicación entre las tres jurisdicciones que intervienen en la cuenca y que no lograban coordinar las acciones sobre el Riachuelo (la creación por ley del Congreso en 2006 de la ACUMAR, un órgano que reúne a todas las jurisdicciones involucradas y oficia como Autoridad de la Cuenca, en coincidencia con la tercera audiencia es una muestra de este vacío); y se centralizó, hizo circular y en algunos casos se produjo la información necesaria para un diagnóstico integral del problema.

Todas estas audiencias fueron de tipo "ordenatorias", como las llamaría la Ac. 30/2007. Si bien la participación fue uno de los ejes tanto del

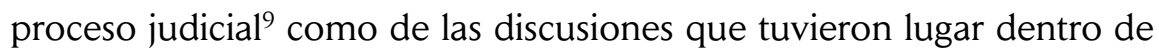
éste; ${ }^{10}$ esta se mantuvo limitada en torno a un grupo de actores expertos y en un tono que mantenía la conversación dentro de los límites de la "razón jurídica profesional" o "la voz desinteresada del derecho" en ocasiones auxiliada por voces de científicos de distinto tenor (Post \& Siegel, 2013, p. 46): los jueces del Tribunal, los abogados, el grupo de terceros

8 Fallos, 329:2316 (20/06/2006).

9 La inclusión de audiencias públicas así como de "terceros interesados" ha sido señalada de manera reiterada como una de las "innovaciones" del caso.

10 Llevar los intereses y preocupaciones de los habitantes de la cuenca a la justicia fue planteado por el Defensor del Pueblo como el aspecto central que lo "movió" a introducirse en el caso; en relación a la Autoridad de la Cuenca se discutió la conformación de la "comisión de participación social" prevista en la propia ley de creación --art. 4, Ley 26.168--) 
que venía trabajando en la problemática de la cuenca y especialistas de las distintas agencias estatales. La voz y el conocimiento de los habitantes de los márgenes del río sobre las condiciones en las que se desarrollaban sus vidas permaneció como un ruido que venía del exterior al espacio judicial, donde se estaban manifestando durante la segunda audiencia de febrero de 2007,"11 o una referencia que era representada como "los afectados" y caracterizada en términos de padecimientos, vulneraciones al derecho a la salud, o como meros espectadores presenciales de las audiencias públicas. Los "afectados" fueron invocados primero, como parte genérica de una "cuestión o área social" que intermitentemente formó parte del Plan que presentó el gobierno, y luego como aquellos que eran representados por el Defensor del Pueblo y las organizaciones de la sociedad civil en términos de derecho a la salud. En ambos casos, los actores de la causa individualizaron a "Villa Inflamable", un barrio delimitado ubicado en la periferia del Polo Petroquímico de Dock Sud a la vera de la cuenca, como la población de referencia en el caso. Correlativamente, el problema del Riachuelo tuvo como eje el derecho al ambiente y la limpieza y el saneamiento de la cuenca.

Con posterioridad a esas primeras cuatro audiencias "ordenatorias", la Corte dictó sentencia de fondo en julio de 2008. ${ }^{12}$ Allí se pronuncia sobre la prevención y recomposición del daño ambiental de la cuenca Matanza-Riachuelo, responsabilizando a los diferentes niveles de gobierno y poniendo en cabeza de ACUMAR la implementación del Plan de Saneamiento que contemplara una serie de objetivos y lineamientos específicos (información pública, contaminación industrial, saneamiento de basurales, limpieza de márgenes de río, expansión de la red de agua potable, desagües pluviales, saneamiento cloacal y plan sanitario de emergencia). Por otro lado, para "fortalecer la participación ciudadana en el control del cumplimiento" del Plan, conformó un "Cuerpo Colegiado" liderado por el Defensor del Pueblo, que reunía a todas las organizacio-

11 Las movilizaciones, protestas y manifestaciones en el exterior del Tribunal acompañaron a las audiencias públicas que se realizaban en el recinto desde el inicio. Pero durante la audiencia de febrero de 2007 las huellas de esas manifestaciones se introdujeron en el interior de la Sala, y en ella se registran varias intervenciones de los magistrados que señalan a "los amigos de afuera" o "el ruido que no deja escuchar" (conf. acta de la audiencia).

12 Fallos, $331: 1622$ (8/7/2008). 
nes que actuaban hasta el momento como "terceros interesados" en la causa, y le otorgó a la Auditoría General de la Nación el rol de control externo de la ejecución presupuestaria del plan. Por último, delegó la ejecución de la sentencia en un juzgado federal de primera instancia con sede en Quilmes para "preservar un significativo grado de inmediatez de la magistratura con los sujetos del caso".

La ejecución de esta inédita sentencia recorrió un largo camino plagado de obstáculos, pero en lo que aquí interesa, el espacio de las audiencias, que inicialmente había generado una serie de narrativas particulares del caso que excedieron el planteo inicial de un grupo de vecinos, también fue el espacio en el que se reformularon los términos en los que el Tribunal había definido tanto el problema como el encuadre jurídico después de la sentencia. Así, las audiencias se convirtieron en un espacio en el que se desarrolló un "microrrelato" denso "dentro del relato del caso" (Berros, 2012, p. 121), en el que se tensionaron al menos "dos narrativas del conflicto: la necesidad de limpiar el Riachuelo y las necesidades de la gente que vive en sus márgenes" (Puga, 2012).

Si bien la sentencia de la Corte solo contemplaba a las "poblaciones afectadas" y la posibilidad de su "relocalización" en dos momentos aislados, ${ }^{13}$ esas poblaciones y su reubicación serían uno de los ejes de la ejecución del plan que se desarrolló en la sede del Juzgado Federal de Quilmes entre 2008 y 2012. Este período post-sentencia puede subdividirse a su vez en dos momentos o etapas marcadas por la resolución del Tribunal del 19/12/2012, donde expresamente se cierra una etapa de la ejecución, en la que el caso adquiere nuevas dimensiones vinculadas en forma directa a "la población en riesgo" que habita la cuenca y, sobre todo, la cuestión de la "participación" social en el proceso se anuncia como central. ${ }^{14}$ La audiencia del 30 de noviembre de 2016 es la primera realizada en esta segunda etapa, que de algún modo la inaugura,

13 El primero es entre una enumeración de ítems variados sobre los que la Corte consideró que no existía información suficiente (cons. $12^{\circ}$ ); el segundo, bajo el acápite referido a la contaminación industrial, junto a las relocalizaciones de empresas del Polo Petroquímico (cons. $17^{\circ}$, pto.III.9) e implícitamente al referirse allí a la urbanización de villas y asentamientos precarios (cons. $17^{\circ}$, pto.III.10). Asimismo, de manera general el programa de saneamiento que debía rediseñar y cumplir la Autoridad de la Cuenca tenía como uno de sus tres objetivos "la mejora de la

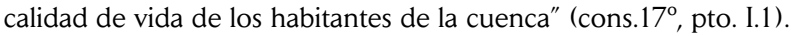

14 Véase el cons. $6^{\circ}$, resolución del 19/12/2012. 
coincidiendo con la nueva composición del supremo tribunal, como se mencionara anteriormente.

En efecto, entre el final de la primera etapa de ejecución y de lleno en la segunda etapa, la cuestión de la participación procesal efectiva de los "afectados" se volvió un tema de discusión por derecho propio. Por tres veces, entre 2012 y 2016, entre la última jornada de audiencia de supervisión del 1/11/2012 y la audiencia de supervisión de 30/11/2016 que aquí queremos destacar, se planteará formalmente en la causa que los vecinos afectados sean escuchados en las audiencias públicas ante la Corte, siempre con resultado negativo. Merlinsky destaca de manera semejante este giro "participativo" en la causa propulsado por los vecinos:

"[eln la audiencia pública celebrada por la CS], el 1 de noviembre de 2012, el conflicto se puso en evidencia cuando los habitantes de la villa 21-24 se hicieron presentes para reclamar su incidencia en la toma de decisiones sobre su destino habitacional. La Defensoría del Pueblo de la Nación, haciéndose eco de estas demandas, propuso a la CSJ, la realización de una audiencia pública exclusiva con los vecinos afectados, para promover un efectivo acceso a la información y participación en las políticas públicas que los involucran" (Merlinsky et al., 2014, p. 203). ${ }^{15}$

Quizás un antecedente de la nueva centralidad que asume la participación de los vecinos sea su presencia en el exterior de la Sala de $\mathrm{Au}^{-}$ diencias y del edificio de tribunales durante las primeras audiencias de 2006 y 2007, con pancartas, cantos, proclamas y folletos; también puede ser el resultado de que aproximadamente desde 2010, y sobre todo a partir de 2011, el expediente aparezca plagado de "notas" y "cartas" de vecinos de los distintos barrios de la cuenca que informan y denuncian vulneraciones de derechos, a veces incluyendo fotos para explicar por qué determinada obra fue incorrectamente realizada o sobre los efectos nocivos que tuvo en su hábitat cotidiano.

15 En esa ocasión, el coordinador del Cuerpo Colegiado de la causa solicita en forma oral que se convoque "con urgencia a una audiencia especial que tenga por objeto analizar exclusivamente la problemática de las relocalizaciones mencionadas en la cual será indispensable que participen representantes de cada una de las comunidades afectadas" (audiencia pública del $1 / 11 / 2012$ ). 
En ese marco no fue una presentación aislada aquella que, unos días antes de la audiencia que presenciamos, hizo la Defensoría de la Ciudad representando a un grupo de más de 60 vecinos de la cuenca, titulándola "Solicitan participación en audiencia". Allí requerían que "Isle provea un mecanismo de participación directa de los afectados en la Audiencia Pública, para que nuestra voz sea escuchada en forma presente y sin intermediación institucional" ${ }^{16} \mathrm{El}$ pedido no fue atendido por el Alto Tribunal y en esas condiciones se celebró la audiencia.

\section{La audiencia pública}

Como señalamos en las líneas introductorias, la audiencia pública del 30 de Noviembre de 2016 resultó el disparador para elaborar una reflexión "contextualmente ubicada" (Muzzopappa \& Villalta, 2011, p. 19) acerca del modo en el que la Corte Suprema traduce en la práctica su decisión de abrir el proceso judicial a la participación ciudadana. Según lo expuesto en la sección anterior, la causa Mendoza resulta paradigmática para el abordaje de esta cuestión no solamente por la complejidad de los asuntos involucrados y su tratamiento por la Corte, sino porque su desarrollo también da cuenta de cómo las prácticas de los actores involucrados, incluido el propio tribunal, reflejan diferentes concepciones y modalidades de los actores para llevar adelante esa participación, poniendo en escena las tensiones que el constitucionalismo desarrolló desde sus inicios. En lo que sigue nos interesa partir de dos escenas que recuperamos de nuestro trabajo de campo, para pensar a partir de ellas cómo en las audiencias se ponen en juego esas tensiones entre la razón profesional del derecho y los repertorios participativos de la política, y entre la voluntad de centralizar el derecho en las Cortes y la dispersión del sentido que se genera en sociedades plurales y democráticas.

16 Muchos de los vecinos que firman ese escrito se hicieron presentes el día de la audiencia pública (conf. fs.4421/4425 del expediente principal). 


\section{"Esto no es una asamblea, es una audiencia en un tribunal". Entre el derecho y la política}

La audiencia pública en la causa Riachuelo había comenzado a las 10 de la mañana del miércoles 30 de Noviembre de 2016, y se celebraba en el sitio habitualmente asignado para este tipo de eventos: la sala de audiencias de la Corte Suprema, ubicada en el cuarto piso del Palacio de Tribunales, ubicado en la CABA. ${ }^{17}$ Junto a esta sala, en el denominado Patio de Honor (en adelante, PH), se había colocado una pantalla grande dispuesta frente a varias filas de asientos totalmente ocupadas, para transmitir en vivo la audiencia pública. La organización del espacio del $\mathrm{PH}$ dispuesta por la Corte reproducía la estética de la gran sala de audiencias: al frente, el sector de los magistrados se reconvierte virtualmente en la pantalla; frente a ella, las filas de sillas para el público también formaban dos conjuntos separados por un pasillo. Allí, sentados en algunos casos y de pie a los costados de los asientos, se ubicaban algunos pobladores de la cuenca Matanza-Riachuelo cuyas vidas se vieron atravesadas por el caso. Estos actores, pertenecientes a varias villas y asentamientos que rodean la cuenca baja y media sobre el margen de la CABA, llevaron consigo al acto de la audiencia medios de expresión considerados inusuales para los espacios tribunalicios, sobre todo para la solemnidad cortesana. En algunos casos usaban remeras con inscripciones de distintos colores que identifican a varias organizaciones de base; en otros, carteles con fotos que mostraban el estado de contaminación de la cuenca o en los que se leían reivindicaciones y reclamos por el impacto de la contaminación en su salud o relacionados con su derecho a la vivienda; otro grupo repartía folletos que explicaban la situación de la cuenca. Según nos relataron luego vecinos y referentes de una de las villas que rodean la cuenca (Villa 21-24), que es a la vez una de las más pobladas del país, y agentes de la Defensoría de la CABA que llevan adelante la defensa de sus derechos, la estrategia era "llevar algo porque sabían que no iban a poder hablar" ni participar formalmente en la audiencia (Vecinos de la cuenca, comunicación personal, agosto de 2017). Entonces llevaron las fotos de la cuenca que habían sido parte de una muestra sobre el Riachuelo, y varios

17 Para una descripción de esa sala de audiencias, ver Benedetti y Sáenz, 2016, pp. 127 y ss. 
folletos impresos que resumían una de las presentaciones que habían hecho en el expediente, junto con pedidos formales infructuosos para participar con voz en ellas. En esa presentación previa en el expediente, denunciaban que el proceso que afectaba sus vidas se estaba llevando adelante sin su participación procesal -los vecinos de la cuenca no eran parte del proceso, y no podían entonces intervenir en las decisiones- y tampoco participaban con voz en las audiencias. Allí "ratificalban] que no somos (no debemos ser) el mero objeto de decisiones administrativas o judiciales, sino personas que tenemos derecho a participar en las decisiones de política pública que impactan directamente sobre nuestras condiciones de vida" (Entrevistado, comunicación personal, septiembre de 2017) ${ }^{18}$. En este mismo sentido, a lo largo de este trabajo escuchamos en repetidas oportunidades y a través de medios diferentes, la proclama de los vecinos de que ellos "querían ser vistos como parte de la solución y no ser tomados como parte del problema"(Vecinos de la cuenca, comunicación personal, noviembre de 2017).

Tanto el pedido formal de participación, como el repertorio que usaron para participar "informalmente", esta vez en el corazón del Palacio de Tribunales porteño, son parte de una larga cadena de intentos de intervención que habían comenzado casi con el caso mismo; sin embargo, estos intentos no habían sido tenidos en cuenta y se podría decir que desde sus inicios les había dado la espalda.

La intervención de los vecinos en la audiencia del 30 de noviembre no se limitó al despliegue de los carteles, fotos y remeras con inscripciones que llevaron al Palacio de Justicia. Muchos aplaudían cuando, desde la pantalla ubicada en el $\mathrm{PH}$, observaban y escuchaban a algún orador denunciar que las obras no habían concluido, o que las relocalizaciones que les habían prometido durante el transcurso del proceso no habían tenido lugar. Mientras tanto, tres de ellos habían logrado ingresar al interior de la Sala de audiencias, y se levantaban voces de protesta cuando los oradores que representaban a alguno de los niveles de gobierno implicados en el cumplimiento del caso - el Estado Nacional, la provincia o la CABA- se referían el cumplimiento de alguna obra en realidad incompleta, o a la

18 En el mismo sentido, ver la solicitud presentada por el Ministerio Publico de la Defensa de la Ciudad de Buenos Aires, el 29/11/2016, en el expediente de la causa. 
falta de cumplimiento de algún programa cuya demora atribuían a los vecinos. Dichas protestas eran las de dos vecinos delegados de la Villa 21-24 y una integrante de una organización no gubernamental con trayectoria de trabajo en ese barrio. En las entrevistas realizadas con ellos, nos cuentan que alzaron su voz para denunciar que los representantes del Estado "mostraban fotos falsas" en la audiencia de la Corte, y que incluso una de ellos intentó acercarse al estrado donde se ubicaban los jueces para entregarle al entonces presidente del tribunal el folleto sobre la situación real de la cuenca que repartían los otros vecinos afuera a distintos funcionarios.

Ante esas intervenciones inusuales en el foro judicial que el acta de la audiencia consignó simplemente como "manifestaciones del público", el tribunal ordenó "que se callen", "ante la próxima interrupción serán desalojados", "esto no es una asamblea, es una audiencia en un tribunal". Sin embargo, en el Patio de Honor al mismo momento, se escuchaba el reclamo contrario, un reclamo por la intervención de la justicia ante la inacción de los poderes políticos asociados a "la asamblea": "iJusticia! iqueremos justicia!", “iHablemos de derechos!".

El imperativo del tribunal refleja una intuición extendida en nuestro pensamiento constitucional, sobre todo aquel referido a la tarea y el rol de las Cortes, y al lugar correlativo de la ciudadanía en relación a las decisiones judiciales y a la interpretación constitucional. El núcleo de esa intuición separa de manera tajante el derecho de la política, la "asamblea" del "tribunal" en palabras del juez, la "Corte" del "pueblo", de manera que ambos espacios se mantienen incomunicados. Robert Post y Reva Siegel formulan esta intuición extendida señalando que "el derecho constitucional define su integridad precisamente en términos de su independencia de la política. Desde la perspectiva interna del derecho, la distinción entre el derecho y la política es constitutiva de la legalidad" (Post \& Siegel, 2013, p. 57). Cada espacio mantiene sus reglas del discurso y selecciona con ellas de manera más o menos explícita, a los participantes en él, de manera que la autoridad de los tribunales “consiste en expresar 'qué es el derecho', y el contenido del mismo debe estar determinado 'esencialmente por el trabajo de los abogados [...], el cual acontece dentro de un espacio de 'principios y lógica' desde el cual todas las consideraciones políticas son excluidas rigurosamente" 
(Post E Siegel, 2013, p. 57). Desde esa perspectiva, el lugar de la ciudadanía queda reservado a "la obediencia a la ley y la deferencia hacia los profesionales" que son "particularmente valoradas" (Post \& Siegel, 2013 p. 46). Las reacciones inusuales de los ciudadanos afectados por la contaminación de la cuenca Matanza-Riachuelo, y también por las medidas tomadas por el gobierno en el caso, desde este punto de vista, aparecen como una amenaza tanto para la integridad y la independencia del derecho, como para la autoridad de los tribunales y la Corte en particular.

Post y Siegel llaman a esta perspectiva "juriscéntrica"; consideran que estrecha demasiado la vida del derecho hasta llegar a confundirlo con las decisiones de los tribunales, dejando fuera de toda consideración que la legitimidad de las constituciones depende en última instancia de que los ciudadanos la reconozcan como propia y puedan enlazarla a valores importantes que guían la vida social. Ellos sugieren entonces girar la perspectiva desde los tribunales hacia otra que incluya a los ciudadanos, que llaman "perspectiva sistémica del ordenamiento constitucional" y la incluyen dentro de lo que proponen como el "constitucionalismo democrático". Desde esta perspectiva, la vida del derecho ha sido -y debe sersensible a la opinión de la ciudadanía, y a aquellos actos inusuales o de resistencia a las decisiones judiciales, que deben tomarse particularmente en serio como "actos que procuran mantener la sensibilidad democrática del significado constitucional" (Post \& siegel 2013, pp. 51-52).

Teniendo en cuenta lo anterior, las audiencias dejan de ser un sitio para delimitar el espacio judicial, mostrarlo al público y reafirmar sus límites frente a la ciudadanía, para transformarse en sitios de privilegio donde se negocia la tensión que genera la necesidad de mantener la integridad del derecho y la razón jurídica profesional que la asegura, y por otro lado, la necesidad también acuciante de contar con legitimidad democrática y ser sensible a las voces de la ciudadanía. De manera correlativa, la reacción inusual y los modos no habituales de participación en foros tribunalicios de los vecinos de la cuenca Matanza-Riachuelo que deseaban expresar su desacuerdo con la manera en que la Corte estaba llevando adelante el caso, ya no aparecen como amenazas a la autoridad judicial o la integridad del derecho, sino que pueden presentar aspectos beneficiosos para la vida institucional del derecho en sociedades plurales y también para repensar los términos del diálogo constitucional. 
Las interrupciones de los pocos vecinos presentes allí a los oradores y a la secuencia de preguntas y respuestas que guiaba el tribunal, así como la presencia de muchos de ellos en el PH para seguir la audiencia pública, demuestra tanto un desacuerdo y una irrupción en el ámbito judicial, como un compromiso con el derecho y con el mantenimiento de la autoridad de los tribunales para hacerlo respetar. De hecho, estos vecinos no dejaron de recurrir a herramientas procesales adecuadas para hacer oír sus voces, más allá de que sus esfuerzos hayan resultado infructuosos. En el mismo sentido, en nuestras entrevistas, los vecinos expresaron este punto que Post y Siegel (2013) consideran un "dilema" de quienes quieren "cambiar el contenido del derecho constitucional": "tienen que lograr que los tribunales acepten sus propios valores constitucionales, pero sin embargo, tienen que mantener la autoridad de los tribunales para defender la Constitución en el nombre de un estado de derecho independiente" (p. 58).

Los vecinos, sus abogados de la Defensa Pública y los integrantes de las ONG con trabajo en el territorio que entrevistamos señalaron que ésta, así como las sucesivas audiencias a las que convocó la Corte, constituían un evento significativo para los habitantes de la cuenca: antes de las audiencias ellos organizaban reuniones para intercambiar opiniones que llegaron a convertirse en espacios de circulación de saberes entre los distintos barrios que rodean la cuenca que antes permanecían incomunicados, y luego de ella discutían los aspectos salientes. Nuestros interlocutores consideraban valiosa la intervención de la Corte en la causa, aunque discordaban con lo que el caso y el derecho significaban en él. Desde su perspectiva, la audiencia pública que los mantenía al margen como oradores y participantes, se presentaba más que como un espacio cerrado donde se ponía en escena la delimitación del derecho y lo que queda fuera de él -la política, la "asamblea", el pueblo-, como un espacio "de experimentación" donde se negocian esos límites. En ese contexto, se entiende que frente al imperativo del presidente del Tribunal que les ordena callar, porque "esto no es una asamblea, es una audiencia en un tribunal"; los vecinos casi en respuesta expresan que justamente quieren "justicia" y "hablar de derechos" y en esa respuesta "ponen en acto su compromiso con la importancia del derecho constitucional" que se debatía en el caso. 
Por otro lado, si las audiencias son uno de los espacios privilegiados donde se negocia la necesidad de"incorporar las creencias populares en el ámbito de la legalidad y al mismo tiempo [se] mant[iene] la fidelidad a las exigencias de la razón jurídica profesional" y pueden imaginarse entonces como el lugar donde transcurre la "conversación entre la Corte, el pueblo y sus representantes" que proponía Bickel y evocan Post y Siegel (2013), tal como ellos sugieren, "el proceso rara vez es tan civilizado y ordenado como una conversación" (p.57). Los carteles, las fotos de la muestra sobre el estado del Riachuelo que reutilizaron los vecinos de la cuenca en la audiencia que presenciamos, las remeras con inscripciones y los exabruptos que interrumpían a los oradores adentro de la Sala, así como las reacciones en el $\mathrm{PH}$, pueden ser vistos como algo más que obstáculos a la conversación, y los vecinos como algo más que meros "alborotadores", citando a Fillieule y Tartakowsky (2015) en su estudio sobre manifestaciones populares (p.111). Su presencia en la audiencia, ya sea de pie o sentados, aclamando o reprobando, gesticulando, aplaudiendo o manipulando fotografía y carteles, no representa solo una resistencia ante un acto que los excluye, sino que puede considerarse también como una serie de intentos deliberativos que incluyen un repertorio comunicativo diferente al usualmente considerado en los foros cortesanos, y que presiona por redefinir los términos de la conversación constitucional. En este sentido, los vecinos y sus inusuales modos de expresión señalan, por un lado, los límites de una conversación sobre los derechos y la vida institucional modelada idealmente como un "diálogo de gentlemen" o "entre elites" que comparten un mismo registro y reproducen las desigualdades sociales al excluir otros saberes y modos de expresión (Young, 2001); por otro lado, al presionar por entrar a esa conversación que les da la espalda, pujan también por redefinir la norma del discurso jurídico y hacerlo más permeable a la consideración de otros saberes, experiencias y miradas. En la sección siguiente consideramos de qué se trata y en qué consiste esa otra mirada sobre el caso que planteaban los vecinos de la cuenca.

\section{"Desalójenlos". Centralización judicial y dispersión del sentido}

En la misma audiencia ocurrió algo que no se había registrado en actos anteriores de la misma índole, tanto en el caso Mendoza, como 
en otras causas. Sucedió en el momento en que estaban ante el atril exponiendo los avances de la implementación de la sentencia uno de los representantes de los distintos niveles del Estado involucrados. Los ministros de la Corte preguntaban y repreguntaban a distintos funcionarios públicos, esforzándose por aclarar, ante las distintas evasivas, que se trata de una audiencia de supervisión de cumplimiento de una sentencia, que "la sentencia del Tribunal es clara y especifica objetivos de cumplimiento". Luego de varias interrupciones de los vecinos de las zonas más marginales de aquella cuenca que habían logrado ingresar a la Sala como público, y de las varias advertencias del Tribunal para hacerlas cesar, se escucha "todos tienen derecho a la participación [...] pero [...] va a ser desalojado, desalójenlos", y tres personas son conducidas por personal de seguridad de la Corte fuera de la Sala hacia el PH, donde se agrupaban la mayoría de los vecinos que habían llegado para presenciar la audiencia.

Esta escena pone en primer plano dos cuestiones que marcaron el caso Riachuelo: (i) una vocación de la Corte actual, que parece continuar la iniciada por la Corte renovada, por abrir los procesos decisorios a la participación de distintos actores -sobre todo mediante la práctica de las audiencias públicas- como parte de un proceso de reconstrucción de legitimidad luego de la crisis política y social de fines de 2001; (ii) por otro lado, el "desalojo" muestra no solo los límites de la apertura a la participación en los foros de altas instancias judiciales, sino que también vuelve visibles las diversas narrativas que sostienen la legitimidad de la intervención de la Corte en el caso y a la vez desafían tanto su monopolio interpretativo como la independencia y autosuficiencia absoluta que se le ha adjudicado.

Desde las primeras audiencias en el caso, la Corte se esforzó en mantener un único espacio para los intercambios centrado en la Sala de Audiencias del Palacio de Tribunales, ${ }^{19}$ delimitando claramente una serie de interlocutores autorizados para intervenir en la definición del

19 De la misma forma, todas las audiencias públicas realizadas hasta el momento en los distintos casos en las que fueron convocadas tuvieron como sede el famoso cuarto piso del Palacio de Tribunales que la alberga, práctica que contrasta con la decisión de desplazarse de otros tribunales (Benedetti \& Sáenz, 2016, p.127). En el caso Mendoza, se registra un único momento en el que la Corte plasma su voluntad de desplazarse hacia el territorio: antes de la quinta audiencia de junio de 2011, en la resolución del 19 de abril de ese año, expresa la necesidad de "hacer un reconocimiento judicial del territorio". 
problema y del derecho. Así mismo, luego de la sentencia, en la audiencia que presenciamos, condujo el diálogo reafirmando que "la sentencia es clara" y que la discusión de limitaba a "controlar la implementación". No obstante, allí, en el escenario de esa audiencia, también se puso de relieve la multiplicidad de sitios por los que transita y se interpreta el caso, las diferentes narrativas que en él y a partir de él se generan y cómo estas vuelven hacia el espacio de la Corte para disputar no solo lo que el caso y el derecho significan, sino también los términos de la participación que allí se abren. A la luz de estas múltiples narrativas que la audiencia puso en primer plano, el "desalojo" ordenado por el entonces presidente del Tribunal se convierte en mucho más que el acto material de expulsión de tres personas provenientes de las zonas aledañas a la cuenca de la Sala de Audiencias, pues es también un símbolo de las luchas de los vecinos que estaban siendo precisamente desalojados de sus casas a la vera del Riachuelo; además, representala expulsión de toda una visión de lo que estaba en juego en el caso que se gestó a partir de la sentencia del Tribunal.

Robert Cover (2002) llamó a esta capacidad del derecho de dispersarse, circular y crecer en diferentes sitios sociales, "jurisgénesis". Con ello, este autor pretendía rotar la perspectiva usualmente centrada en el Estado y en los tribunales para resaltar las múltiples vidas del derecho o las muchas maneras en las que diferentes actores o comunidades dentro del Estado lo interpretan para darle sentido a sus vidas, sus problemas y sus luchas. Desde esta visión, los tribunales ejercen un rol inverso a la "jurisgénesis" que hace proliferar el sentido del derecho y ofician como instituciones "jurispáticas" que en pos de establecer un único significado con valía estatal, destruyenlas alternativas contendientes. Por otra parte, las audiencias, y la audiencia del 30 de noviembre en particular, pueden ser vistas como sitios en los que se negocia esta tensión en la vida del derecho: por un lado, la necesidad de que florezca el significado jurídico entre la ciudadanía de manera que ellos asuman como propio el derecho y se reconozcan en él; por el otro, la necesidad desde la óptica estatal, de establecer un único derecho y señalaruna serie de instituciones, característicamente los tribunales y la Corte en particular, como la única voz capaz de establecer su significado. 
Desde este punto de vista que mantiene la tensión entre la necesidad de establecer un significado ("la sentencia es clara") y la inevitable proliferación de intérpretes y sentidos, puede releerse el caso a partir de las audiencias.

Así, se podría ver que las primeras audiencias "ordenatorias", como las llamaría la Ac. 30/2007, no solo sirvieron al objetivo instrumental de organizar o "gerenciar" un proceso judicial complejo (Lorenzetti, 2014), sino que también tuvieron el efecto de delimitar un espacio y una serie de interlocutores capaces de definir el problema y de intervenir en las soluciones. Esos interlocutores se ceñían a abogados, jueces y expertos de distinto tenor, incluyendo también a las empresas, pero excluyeron sistemáticamente a los vecinos de la cuenca y su visión de cuál era el problema en el caso que afectaba sus vidas. En este sentido, como se señaló, el problema del caso "Riachuelo" tuvo como eje el derecho al ambiente; y solo marginalmente apareció el problema del hábitat, el derecho a la ciudad o la justicia espacial que se gestaba como narrativa alternativa desde los márgenes del caso: afuera, en las protestas de los vecinos, ${ }^{20}$ y luego también en los espacios de participación que se abrirían en los barrios, villas y asentamientos que rodean la cuenca. ${ }^{21}$

Ese margen inicial al que se confinó la visión de los vecinos y su énfasis en la cuestión habitacional, empezó a presionar con más fuerza

20 En los exteriores de la Corte, se repartían varios folletos que plasmaban reclamos así como propuestas en relación a la cuenca. Conservamos algunos en los que se leen los siguientes proyectos: un plan de "trabajo genuino a los desocupados para realizar el saneamiento", un "programa habitacional", un "plan de mejoramiento de los barrios", y que los "proyectos sean consensuados con los vecinos de los barrios".

21 En este sentido, se ha señalado que "el caso se tramitó como de afectación al derecho a la salud y al derecho al ambiente sano. Las condiciones en las que residían miles de familias a la vera del Riachuelo no constituyeron tema central o motor de este litigio estructural" (Chellillo et al., 2014, p. 24). Por su parte, el estudio etnográfico de Carman con sectores de la población "afectada", muestra cómo "algunos habitantes de [este] entorno problemático apelan a una narrativa ambiental, que suele sumarse a un eje reivindicativo en torno a la vivienda, el territorio o las condiciones generales de vida" (2017, p. 18). Puga señala algo semejante: "antes que el caso cobrara estas dimensiones, la cuestión ambiental estaba al último en la agenda de aquellos vecinos más marginales del área afectada, con altos niveles de NBI (necesidades básicas insatisfechas) y desocupación. Sus principales preocupaciones pasaban, y pasan, por la subsistencia alimentaria, la vivienda, y los servicios básicos. La contaminación del ambiente, aunque grave y causante de diversas afecciones $[. .$.$] , no siempre podía considerarse en pie de igualdad con otro tipo de ur-$ gencias [...], ese escenario político estuvo definido y reglado por las narrativas y la perspectiva de los 'otros', ya sea los expertos en el tema, los juristas que intervienen en el proceso judicial, o incluso la opinión pública porteña" (2012, pp. 79-80). 
sobre el relato central que estableció la Corte en el caso, durante la etapa de ejecución. Durante este momento, a su vez, el espacio de la Corte y de la conversación judicial sobre el problema de la cuenca se abrió para incluir a aquellos tribunales de baja instancia que añadirían otras aristas al problema y enfatizarían nuevos aspectos. De manera lateral, el nuevo rumbo que tomó la ejecución en esta sede también sumó otros espacios de discusión y movilización legal en el territorio mismo de la cuenca y entre los "afectados".22

Cuando la causa llega a Quilmes, el juez se encuentra con un programa que requería definición. En ese marco, ACUMAR presentó, entre diciembre de 2009 y marzo de 2010, el documento que guía la ejecución del caso hasta la actualidad, un Plan Integral de Saneamiento Ambiental (PISA). El PISA estableció 14 líneas de acción sobre la cuenca entre las que se encontraban dos que, aunque ausentes en las discusiones de las audiencias previas y marginalmente presentes en la sentencia, se convirtieron en el centro de la etapa de ejecución: la "limpieza de márgenes" y "la urbanización de villas y asentamientos precarios". Ambas involucran de manera central a la población afectada por la contaminación del Riachuelo. La limpieza de los márgenes del río fue traducida jurídicamente por el juez de ejecución como la "liberación del camino de sirga", una figura del derecho civil que establecía que los propietarios limítrofes con ríos deben dejar libre una franja de terreno de 35 metros hasta la orilla y que en el caso implicaba el desalojo y relocalización de más de 1.500 familias que tenían sus casas sobre la rivera. El resto de los pobladores que habitaban en su mayoría villas y asentamientos precarios esperarían entonces la "urbanización" de su entorno vital.

Ante las irregularidades de los primeros desalojos y en medio de la incertidumbre sobre la relocalización de los habitantes de la cuenca que se sumaba a aquella vinculada a la contaminación ambiental, comienzan a formarse en algunos casos y se fortalecen en otros, distintos espacios

22 Un trabajo elaborado por integrantes de la Defensa Pública de CABA señala que lo "novedoso" del caso es "el hecho de que de la ejecución de una causa judicial surja un colectivo social orientado a la defensa de los derechos de los habitantes afectados por ella" (Chellillo et al., 2014, p. 44). En el mismo sentido, Cravino y Fainstein señalan que la dilatación de la ejecución de la sentencia se tradujo en un aprendizaje por parte de los vecinos en la perspectiva de derechos. Esto implicó la posibilidad de recabar información, desarrollar formas organizativas, consolidar las ya existentes e iniciar negociaciones de los términos de algunas políticas (2017, p. 92). 
de participación entre los vecinos de los asentamientos y villas linderos al Riachuelo (comisiones de vecinos, asambleas de "delegados de la sirga", encuentros barriales) que se reúnen ahora en torno a su condición asignada judicialmente de "afectados". A la par de estos nuevos modos de reunión, afiliación y organización, se suman lateralmente a la causa una serie de "organismos defensores" (Carman, 2017): la Defensoría General de la Ciudadde Buenos Aires, la Asesoría tutelar n 1 ante la Cámara de Apelaciones en lo contencioso y tributario de CABA, y un grupo de ONG que no integraban el "Cuerpo Colegiado"y que se distinguen por tener trabajo en terreno en el área. Allí se gesta una nueva narrativa del caso que excede la limpieza del Riachuelo largamente prometida a la población en general, y aprovecha la designación judicial de "afectados" y la fijación de prioridades en torno al "camino de sirga" para reelaborar la demanda por un hábitat digno y la integración de las villas y asentamientos a la ciudad. Aquello que en la sentencia de la Corte aparecía como dos menciones aisladas, a lo sumo elementos que debía contemplar el Plan y que luego, efectivamente, se incorporaron, era el prisma desde el que los vecinos leían todo el caso. Del mismo modo, la centralidad otorgada a la vieja figura del Código Civil del "camino de sirga", desplazó el foco del barrio delimitado de Villa Inflamable, hacia otros, como la Villa 2124 de Barracas, con una extensa área sobre el camino de sirga, conocida como la más grande y más poblada de la CABA.

Durante la primera etapa de la ejecución, al igual que en las audiencias públicas previas a la sentencia, la Corte se mostró independiente y autónoma en relación con actores políticos y sociales, ejerció un rol fuerte de control de los otros órganos de gobierno, y a la vez, abrió su espacio a la participación de esos actores políticos y sociales mostrándose incapaz por sí sola, de decidir legítima y autoritativamente un caso complejo, de alta visibilidad e impacto social, o de implementar esas decisiones. Mientras que la Corte intentó mantener un espacio único, definido, con interlocutores y reglas de discurso delimitadas, que reafirmarían su carácter de intérprete íntegro y único; la inclusión de otros actores -jueces de ejecución, oficiales y agentes estatales, organizaciones de la sociedad civil, el público de vecinos de la cuenca- trajo con ellos a la vista la extensa red de interlocutores, intérpretes e implementadores 
que las decisiones de la Corte necesitan, y que en ocasiones, desafían los límites que ella impone.

La audiencia del 30 de noviembre planteó de lleno las tensiones que involucra esta necesidad de centralizar y delimitar el espacio de la justicia en la Sala de Audiencias y, por otro lado, la necesidad de abrir ese espacio a la participación de actores políticos y sociales para lograr un compromiso suficiente en la implementación y el reconocimiento social de la sentencia. Mientras en el interior de la Sala los jueces se esforzaban por sostener que la "sentencia de la Corte es clara", en sus márgenes, los vecinos de la cuenca presionaban por redefinir el caso poniendo en escena con su exclusión del espacio del diálogo cortesano su demanda por el reconocimiento de la injusticia espacial que los relega también a los márgenes sociales. El desalojo de la Sala de dos vecinos y una activista social con trabajo en la cuenca, no solo excluyó de la conversación sobre el derecho a tres afectados directos por la decisión; también puso en acto el "desalojo" de la vida ciudadana a la que están confinados los vecinos y cerró las puertas a toda una visión diferente del caso, situada en la experiencia y vivencia directa del conflicto, que venía gestándose en los márgenes del proceso.

\section{Reflexiones finales}

En este trabajo presentamos un análisis de la audiencia pública realizada en noviembre de 2016 en una de las causas más trascendentes de la Corte argentina que, combinando los aportes del método etnográficos con categorías de la teoría constitucional, intentó reflexionar de manera situada sobre los términos de la participación ciudadana que allí se abre. Nuestra participación en ella como observadores y como público entre los vecinos de la cuenca Matanza-Riachuelo que llegaron también allí para presenciarla, nos permitió recuperar dos momentos clave en esa audiencia que ponen en primer plano las tensiones fundantes del constitucionalismo y permiten observar su desenvolvimiento de cerca. Por un lado, en la audiencia que analizamos, se tensionaron los modos de participación y actuación tradicional de las cortes ligadas a la "calma razón profesional" y a la experticia que deja fuera los saberes de los ciudadanos; 
con otros repertorios de participación asociados a la "asamblea", a los foros políticos, y a modos de la protesta usualmente excluidos del ámbito del derecho. Por otro lado, en la audiencia se cristalizó el conflicto que se presenta entre la necesidad de la Corte de mantener el monopolio interpretativo, de afirmar que "la sentencia es clara"; y las múltiples vidas de esa sentencia y del derecho en otros ámbitos sociales que llevaron a la Corte los vecinos de la cuenca Matanza-Riachuelo. El recorrido a través de la audiencia y su contexto, las planteó como sitios clave para observar cómo se negocian esas tensiones en prácticas concretas; y cómo las audiencias pueden funcionar como un espacio de experimentación de los límites entre la política y el derecho que usualmente se separan de manera tajante, y entre el monopolio interpretativo que se le ha adjudicado a la Corte y la diseminación de las narrativas sobre los casos.

\section{Referencias}

Barrera, L. (2012). La Corte Suprema en escena. Una etnografia del mundo judicial. Buenos Aires: Siglo XXI.

Benedetti, M. A. \& Sáenz, M. J. (2016) Las audiencias públicas de la Corte Suprema. Apertura y límites de la participación ciudadana en la justicia. Buenos Aires: Siglo XXI.

Bergallo, P. (2014). La causa Mendoza: una experiencia de judicialización cooperativa sobre el derecho a la salud. En R. Gargarella (comp.), Por una justicia dialógica. El Poder Judicial como promotor de la deliberación democrática (pp. 245-291). Buenos Aires: Siglo XXI.

Berros, V. (2012). Relatos sobre el río, el derecho de la cuenca Matanza-Riachuelo. Revista de Derecho Ambiental (1), 111-163.

Cafferata, N. (2007). El tiempo de las 'cortes verdes'. La Ley, 2007-B, 423-428.

Carman, M. (2017). Las fronteras de lo humano. Cuando la vida humana pierde valor y la vida animal se dignifica. Buenos Aires: Siglo XXI.

Cravino, M. C. \& Fainstein, C. (2017). Disputas por el acceso al ambiente sano y a la vivienda en la ribera del Riachuelo: derechos de los vecinos, acción de la justicia y políticas públicas. En M. Cristina Cravino (coord.), Detrás de los conflictos. Estudios sobre desigualdad urbana en la Región Metropolitana de Buenos Aires (pp. 53-113). Los Polvorines: Ediciones Universidad Nacional de General Sarmiento. 
Chellillo, M., López, M.J., Royo, L., Sagasti, I., E Territoriale, A. (2014). “El 'qué'. Las relocalizaciones en el marco de la causa Riachuelo y el derecho a la ciudad. Revista Institucional de la Defensa Pública de la CABA, (6), 23-40.

Cover, R. (2002). Nomos y narración. En Derecho, Narración y violencia. Poder constructivo y poder destructivo en la interpretación judicial, (pp. 15-111). Barcelona: Gedisa.

Das, V. E Poole, D. (2008). El estado y sus márgenes. Etnografías comparadas. Cuadernos de Antropología Social, (27), 19-52.

Fillieule, O. \& Tartakowsky, D. (2015). La manifestación. Cuando la acción colectiva toma las calles, Buenos Aires: Siglo XXI.

Gargarella, R. (2014). "El nuevo constitucionalismo dialógico, frente al sistema de los frenos y contrapesos". En Roberto Gargarella (comp.), Por una justicia dialógica. El Poder Judicial como promotor de la deliberación democrática, (pp.119-158) Buenos Aires: Siglo XXI.

Gargarella, R. E Bergallo, P. (2014). Presentación. En R. Gargarella (comp.), Por una justicia dialógica. El Poder Judicial como promotor de la deliberación democrática, (pp. 9-13), Buenos Aires: Siglo XXI.

Greenhouse, C. J. (2012). Judgment and the Justice: An Ethnographic Reading of the Sotomayor Confirmation Hearings. Law, Culture and the Humanities, 8(3): 409-432.

Guber, R. (2001). La etnografía. Método, campo y reflexividad. Buenos Aires: Norma. Kramer, L. (2004). The People Themselves.Popular Constitutionalism and Judicial Review. New York: Oxford University Press.

Latour, B. (2004). La fabrique du droit. Une ethnographie du Conseild'État. Paris: La Découverte/Poche.

Lorenzetti, R. (2014). Las audiencias públicas y la Corte Suprema. En R.Gargarella (coord.). Por una justicia dialógica. El Poder Judicial como promotor de la deliberación democrática (pp. 345-354), Buenos Aires: Siglo XXI.

Mendes, C. H. (2013). Constitutional Courts and Deliberative Democracy. Oxford: Oxford University Press.

Merlinsky, G., Montera, C., Spadoni, E., \& Tobías, M. (2014). La causa Beatriz Mendoza: política ambiental y derechos en tensión. En L. Pautassi (dir.), Marginaciones sociales en el área metropolitana de Buenos Aires, (pp. 163-213). Buenos Aires, Biblos.

Muzzopappa, E. E Villalta, C. (2011). Los documentos como campo. Reflexiones teóricometodológicas sobre un enfoque etnográfico de archivos y documentos estatales. Revista Colombiana de Antropología, 47, 13-42. 
Post, R. \& Siegel, R. (2013). Constitucionalismo democrático. Por una reconciliación entre Constitución y pueblo. Buenos Aires: Siglo XXI.

Puga, M. (2008). ¿A dónde va la Corte en las causas Verbitsky y Riachuelo? Ni uñas, ni dientes, intervenciones experimentalistas. Revista CALP, (69), 151-165.

Puga, M. (2012). Litigio y cambio social en Argentina y en Colombia, Buenos Aires: CLACSO.

Tushnet, M. (2015). New institutional mechanisms for making Constitutional Law. Harvard Public Law, Working Paper No. 15-08. Recuperado de http:// ssrn.com/abstract $=2589178$

Young, I. M. (2001). Activist Challenges to Deliberative Democracy. Political Theory, 29(5), 670-690. 